\title{
Process Optimization of EDM Cutting Process on Tool Steel using Zinc Coated Electrode
}

\author{
Hanizam $\mathrm{H}^{1, *}$, N. Mohamad ${ }^{2}$, U.A.A. Azlan ${ }^{1}$, and M. Qamaruddin ${ }^{1}$ \\ ${ }^{1}$ Faculty of Engineering Technology, Universiti Teknikal Malaysia Melaka (UTeM), Hang Tuah Jaya, \\ 76100 Durian Tunggal, Melaka, Malaysia \\ ${ }^{2}$ Faculty of Manufacturing Engineering, Universiti Teknikal Malaysia Melaka (UTeM), Hang Tuah \\ Jaya, 76100 Durian Tunggal, Melaka, Malaysia
}

\begin{abstract}
In WEDM machining process, surface finish quality depends on intensity and duration of spark plasma. Electrode wire diameter has significant effect on the spark intensity and yet the studies on this matter still less. Therefore, the main objectives of this studies are to compare the different diameters of zinc coated and uncoated brass electrode on H13 tool steel surface roughness. The experiments were conducted on Sodick VZ300L WEDM and work piece material of tool steel AISI H13 block. Electrode of zinc coated brass with diameters of $0.1 \mathrm{~mm}, 0.2 \mathrm{~mm}, 0.25 \mathrm{~mm}$ and uncoated brass $0.2 \mathrm{~mm}$ were used. The surface roughness of cutting was measured using the SUR-FTEST SJ-410 Mitutoyo, surface roughness tester. The results suggest that better surface roughness quality can be achieved through smaller electrode wire diameter. The zinc coated improves flushing ability and sparks intensity resulting in better surface finish of H13 tool steel. New alloys and coating materials shall be experimented to optimized the process further.
\end{abstract}

\section{Introduction}

In die making industries, $\mathrm{H} 13$ tool steel which has high wear resistance and thermal shock is commonly used as die material and requires high precision cutting process. Hence, wire electrical discharge machining (WEDM) has been adopted to tackle this requirement. WEDM uses a thin single-strand metal wire to cut a conductive work piece that submerged in dielectric fluid. It uses electro-thermal energy to cut with high dimensional accuracy and surface finish. The high quality surface improves wear resistance, corrosion resistance and fatigue strength of work piece [1]. Moreover, brass is common material used as wire compared to copper, molybdenum and tungsten as more cost effective electrode material. However, in recent years, the development of alloys and coating technologies have led to more robust and improved materials, such as, zinc coated brass wire [2]. The coated wire also helps to protect the brass from thermal shock and broken [3]. In addition, the coated wire able to increase machine productivity by $70 \%$ over uncoated brass wire [4].

* Corresponding author: hanizam@utem.edu.my 
The electrode wire performances are normally measured on two machining responses, material removal rate (MRR) and surface roughness $(\mathrm{Ra})$ and the corresponding input parameters studies by most were current, pulse on time, pulse off time, wire feed and wire tension $[3,5,6]$. Observations made by several works showed that Ra of $\mathrm{H} 13$ tool steel increases when the electrode wire tension, pulse off time and servo voltage increased, and decreases with the increases of electrode wire feed, pulse on time and peak current $[7,8]$. Furthermore, the MRR shall increase when pulse on time and peak current increases [9]. Since the surface finish quality depends on intensity and duration of spark plasma, another important input parameter such as electrode wire size is always neglected. The studies conducted on wire diameter to surface finish is still less. Therefore, the main objectives of this study are to compare the different diameters of zinc coated and uncoated brass electrode on H13 tool steel surface roughness.

\section{Research methodology}

The experiments were conducted on Sodick VZ300L WEDM and work piece material of tool steel AISI H13 block of $100 \mathrm{~mm} \times 50 \mathrm{~mm} \times 20 \mathrm{~mm}$. The tool steel melting point and tensile strength were $2600 \mathrm{OF}$ and $1990 \mathrm{MPa}$, respectively. Two type of electrode wires were investigated, brass with tensile strength and thermal conductivity of $1000 \mathrm{~N} / \mathrm{mm} 2$ and $109 \mathrm{Watt} / \mathrm{mK}$, respectively and with diameters of $0.2 \mathrm{~mm}$. Zinc coated brass of $883 \mathrm{~N} / \mathrm{mm} 2$ and $20 \mathrm{Watt} / \mathrm{mK}$ with diameters of $0.1 \mathrm{~mm}, 0.2 \mathrm{~mm}, 0.25 \mathrm{~mm}$ [5]. Process parameters applied for all samples were current $<20 \mathrm{~A}$, electrode feed rate $420 \mathrm{~mm} / \mathrm{sec}$, voltage $120 \mathrm{~V}$ and submerged into dielectric of distilled water [10]. The surface roughness of cutting was measured using the SUR-FTEST SJ-410 Mitutoyo, surface roughness tester. Analysis data were carried out using Minitab17 software.

\section{Result \& discussion}

\subsection{Surface roughness comparison of zinc coated brass electrode diameters}

Based on $95 \%$ of confident level, two-sample T-test has been conducted to compare the 3 pairs of surface roughness taken at $0.1 \mathrm{~mm}, 0.2 \mathrm{~mm}$ and $0.25 \mathrm{~mm}$ diameters. The P-values $(<0.05)$ obtained from each pair shown significant different of the means and also shown in the boxplot diagram in Fig.1: 


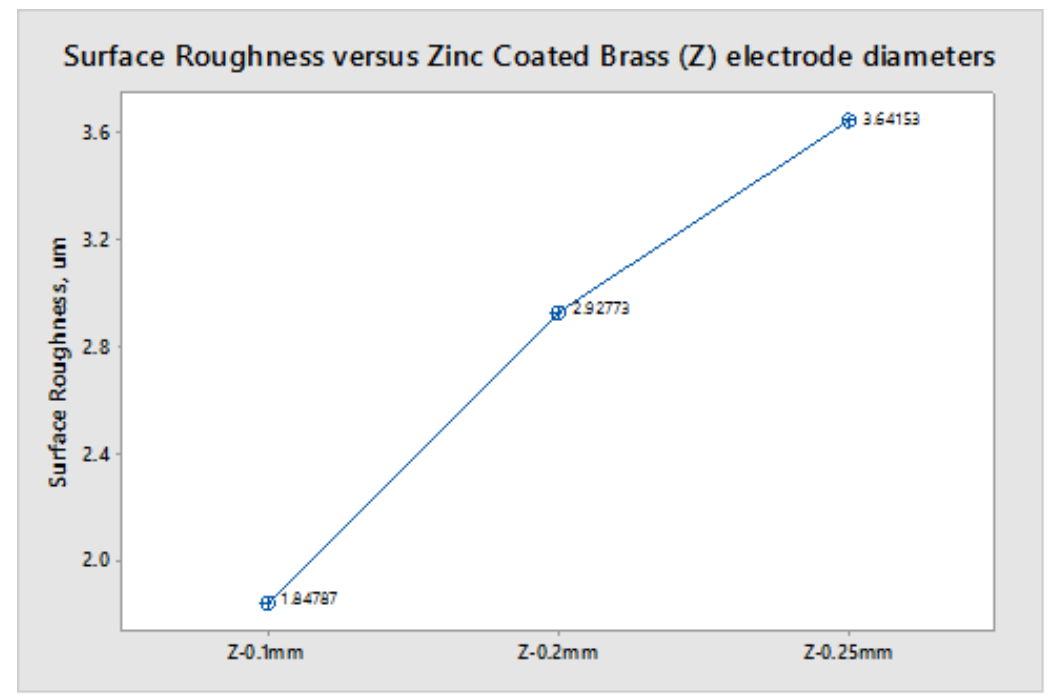

Fig. 1. Surface Roughness of H13 material using different wire diameters

The surface roughnesses of cutting area were affected by the diameter of electrode wires. The results showed that the surface roughness increases almost linearly with electrode diameter. The SR value increases from 1.847 um to 3.64 um respectively. Similar observations have been made by other work on mild steel workpiece material cut using two brass wire diameters of $0.3 \mathrm{~mm}$ and $0.2 \mathrm{~mm}$ [11]. The $0.2 \mathrm{~mm}$ diameter's surface roughness reduced by $40 \%$ compared to $0.3 \mathrm{~mm}$ diameter from $2.5 \mathrm{um}$ to $3.5 \mathrm{um}$, respectively.

The surface roughness might be influenced by the heat affected zone sparks during cutting process. The larger the diameter causing higher spark intensities, therefore resulting in more penetration and large amount of material being removed [12].

\subsection{Surface roughness comparison between brass and zinc coated brass electrode}

The comparison has been made on similar $0.2 \mathrm{~mm}$ diameter of both electrode materials. Two-sample T-test have been conducted and the result as follow;

\begin{tabular}{|c|c|c|c|c|}
\hline Electrode & $\mathrm{N}$ & Mean & StDev & SE Mean \\
\hline B- $0.2 \mathrm{~mm}$ & 15 & 3.375 & 0.123 & 0.032 \\
\hline Z-0.2mm & 15 & 2.928 & 0.0735 & 0.019 \\
\hline
\end{tabular}

Difference $=\mu($ B-0.2) $-\mu(\mathrm{Z}-0.2)$

Estimate for difference: 0.4477

$95 \%$ CI for difference: $(0.3709,0.5245)$

$\mathrm{T}$-Test of difference $=0(\mathrm{vs} \neq): \mathrm{T}-$ Value $=12.09 \quad \mathrm{P}-$ Value $=0.000 \quad \mathrm{DF}=22$

The P-values $(<0.05)$ obtained shown significant different of the means and also shown in the boxplot diagram in Fig.2: 


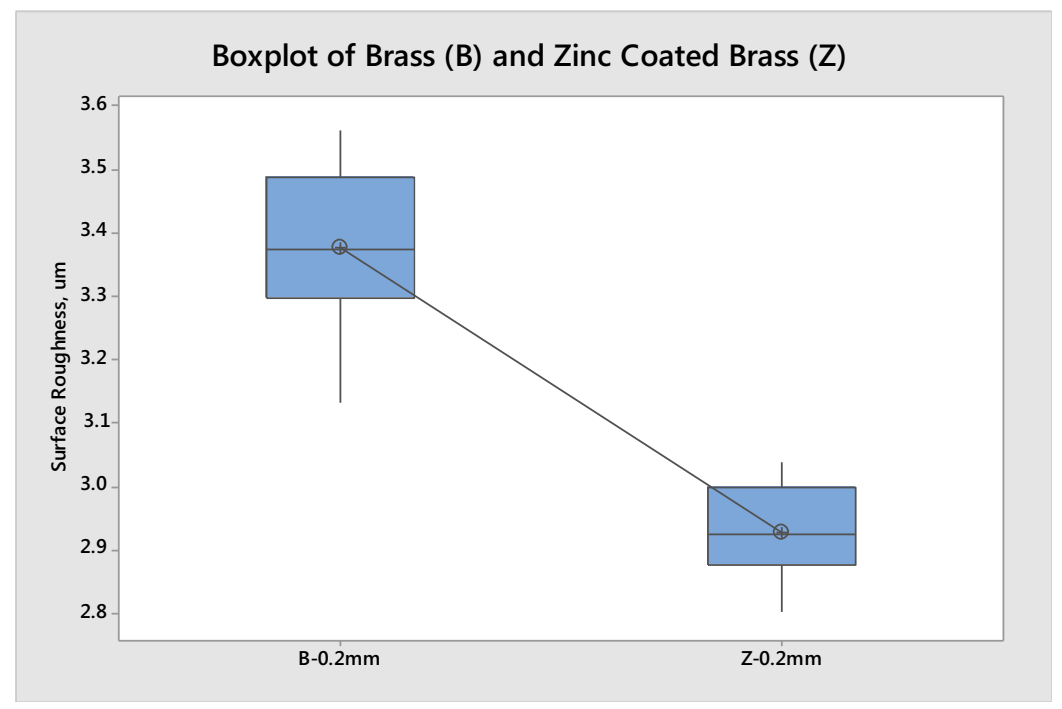

Fig. 2. Surface roughness comparison between coated and uncoated electrode wire

The tool steel machined using zinc coated brass produced better surface quality compared to brass wire and similar to other work [12]. It is due to the formation of surface profile, decreased dielectric flushing ability and zinc coated also acts as coolant to minimize surface modification. The ineffective flushing result in poor surface finishes [3].

As a proven method for the result, the value of surface roughness for both wires is compared graphically by time series plot graph (Figure 2). By refer to the graph; the surface roughness value for zinc coated brass is definitely lower than brass wire electrode. Similar conclusion made by other author when comparing the SR of INCONEL 600 material cut using $0.25 \mathrm{~mm}$ brass and zinc coated brass wires [13]. Zinc coated brass wire also given the optimum result when comparing brass, zinc coated brass and molybdenum wires.

\section{Conclusions}

This study set out to examine the relationship between the surface roughness and electrode diameters. These data suggest that better surface roughness quality can be achieved through smaller electrode wire diameter on top of electrode wire tension, pulse off/on time, servo voltage, electrode wire feed, and peak current. Indirectly, it might be useful to the die making industry to save some cost on the wire. Another important finding, in general, it seems that the zinc-enriched outer coating of brass improves flushing ability and sparks intensity resulting in better surface finish of $\mathrm{H} 13$ tool steel.

The authors would like to acknowledge Universiti Teknikal Malaysia Melaka (UTeM) and Ministry of Higher Education Malaysia for sponsoring this study under a Short Term Research Grant Scheme (PJP/2014/ FTK (13B)/S01328). 


\section{References}

1. J. Singh, S. Sharma, Int. J. of Current Eng. and Tech., 1852-1857, (2013)

2. M. Manjaiah, S. Narendranath, S. Basavarajappa, V.N. Gaitonde, Precis. Eng., 41, 68 (2015)

3. J. Kapoor, S. Singh, J.S. Khamba, Proc. World Congr. Eng., 2, 1 (2010)

4. D. Thomas, R. Kumar, G.K. Singh, P. Sinha, S. Mishra, Materials Today: Proceedings. 2, $3520(2015)$

5. B.K. Lodhi, S. Agarwal, Procedia CIRP., 14, 194 (2014)

6. V. Singh, S.K. Pradhan, Procedia Eng., 97, 1597 (2014)

7. M.T. Antar, S.L. Soo, D.K. Aspinwall, D. Jones, R. Perez, Procedia Eng., 19, 3 (2011)

8. J.R. Mevada, Int. J. Sci. Eng. Res., 4,1398 (2013)

9. Ashok Kumar Choudhary, Prof. K.K. Chhabra, Int. J. Res. Dev. Eng. Sci. \& Manage., 1, 72 (2014)

10. D. Ghodsiyeh, A. Golshan, J.A. Shirvanehdeh, Indian J. Sci. Technol., 6, 4128 (2013)

11. A.A. Khan, M.B.M. Ali, N.B.M. Shaffiar, J. Appl. Sci., 6, 2317 (2006)

12. K. Kanlayasiri, P. Jattakul, Precis. Eng., 37, 556 (2013)

13. G. Amitesh, K. Jatinder, Int. J. Adv. Eng. Technol., 3, 170 (2012) 